\title{
The impact of obesity and smoking on young individuals suffering from lumbar disc herniation: a retrospective analysis of 97 cases
}

\author{
Sara Lener ${ }^{1}\left(\mathbb{D} \cdot\right.$ Christoph Wipplinger $^{1} \cdot$ Sebastian Hartmann $^{1} \cdot$ Claudius Thomé $^{1} \cdot$ Anja Tschugg $^{1}$
}

Received: 9 January 2019 / Revised: 4 March 2019 / Accepted: 24 July 2019 / Published online: 14 August 2019

(C) The Author(s) 2019

\begin{abstract}
The negative impact on spinal diseases may apply not only to obesity but also to smoking. To investigate the influence of obesity and smoking on the development and recovery of lumbar disc herniation in young adults. Retrospective analysis of 97 patients who presented with lumbar disc herniation at the authors' department between 2010 and 2017. Data were collected using the patients' digital health records including demographics, clinical and neurological characteristics, treatment details, and outcomes. Ninety-seven patients between 17 and 25 years were included in this retrospective analysis. Patients were categorized into two groups according to their body mass index: obese $\left(\mathrm{O}, \geq 30 \mathrm{~kg} / \mathrm{m}^{2}\right)$ and non-obese $\left(\mathrm{NO},<30 \mathrm{~kg} / \mathrm{m}^{2}\right)$. The proportion of obese patients in our cohort vs. in the overall population differed significantly (19.4\% vs. 3.8-7.1\%, RR 3.17; $p<0.01)$. Group NO showed a trend toward faster recovery of motor deficits $(p=0.067)$ and pain $(p=0.074)$. Also, the proportion of regular smokers differed significantly from the numbers of known smokers of the same age (62.4\% vs. $30.2 \%$, RR $2.0 ; p=0.01)$. Obesity plus smoking showed a significantly negative impact on motor deficits postoperatively $(p=0.015)$ and at discharge $(p=0.025)$, as well as on pain values $(p=0.037)$ and on analgesic consumption $(p=0.034)$ at 6 weeks follow-up. The negative impact of obesity and smoking on the occurrence of lumbar disc herniation could be demonstrated for individuals aged 25 or younger. Furthermore, a trend to earlier recovery of motor deficits and significantly lower pain scales for non-obese and non-smoking patients could be shown.
\end{abstract}

Keywords Obesity $\cdot$ Smoking $\cdot$ Young adults $\cdot$ Adolescent $\cdot$ Lumbar disc herniation

\section{Introduction}

Obesity is a growing pervasive disease in developing countries, and its prevalence might rise in future decades, especially in young adults [1]. Currently, obesity affects $3.8-7.1 \%$ of young adults in Central Europe [2,3] and is defined as a body mass index (BMI) above $30 \mathrm{~kg} / \mathrm{m}^{2}$. The impact of obesity on spinal and musculoskeletal disease (i.e., lower back pain, facet joint degeneration, and intervertebral disc degeneration) has been demonstrated in numerous previous studies $[4,5]$. Influences were also detected for juvenile disc degeneration [6]. However, data on the impact of obesity on the treatment of lumbar disc herniation (LDH) for adolescents is lacking. Although an increased perioperative risk could be

Sara Lener

sara.lener@i-med.ac.at

1 Department of Neurosurgery, Medical University of Innsbruck, Innsbruck, Austria demonstrated in previous trials $[7,8]$, spinal surgery is presented as the treatment of choice with favorable outcomes in obese patients [9]. The management of LDH may be more challenging in young individuals since surgical indications are restricted, even though operative treatment shows a good outcome in adolescents $[10,11]$. The outcome after lumbar sequesterectomy may be influenced by various other factors including gender and preoperative lifestyle habits $[12,13]$. In addition to obesity, smoking also represents an important factor that influences the health of young individuals, as nearly one-third of people aged 30 and younger in Central Europe are regular smokers [14]. Smoking habits were found to have a negative impact not only on the development of LDH $[15,16]$, but also on re-herniation rates [17]. Nevertheless, the impact of smoking on recovery, especially in adolescents, is not clear. Also, the question whether an elevated BMI precedes or follows first clinical manifestations could not be answered yet. Therefore, the purpose of this retrospective study was to detect differences between obese and non-obese, and smoking and non-smoking young adults suffering from LDH, in terms of 
clinical features (i.e., time of diagnosis, motor deficits, pain scales, treatment details) and outcome.

\section{Material and methods}

A retrospective analysis of patients aged between 17 and 25 years $(22.3 \pm 2.2)$ treated with sequestrectomy for LDH between 2010 and 2017 at the author's department was done. Patients were categorized into two groups according to their BMI: group obese $(\mathrm{O}, \geq$ $30 \mathrm{~kg} / \mathrm{m}^{2}$ ) and group non-obese $\left(\mathrm{NO},<30 \mathrm{~kg} / \mathrm{m}^{2}\right.$ ). Additionally, three subgroups were created: group $\mathrm{O} 1$, obese and heavy smoking ( $\geq 20$ cigarettes per day); group $\mathrm{O} 2$, obese and smoking $(<20$ cigarettes per day); group $\mathrm{O} 3$, obese + non-smoking. These groups (consisting of 6 patients each) were analyzed separately. A subgroup analysis of smoking/non-smoking non-obese patients was not done concerning this study, as it is part of a separate investigation, dealing with the smoking status only.

The diagnosis was based on clinical and magnetic resonance imaging (MRI) parameters. Due to the patients' young age, computed tomography (CT) was renounced. Patients were treated according to the guidelines of the German Society of Neurosurgery (DGNC) and the German Society of Orthopedics and Orthopedic Surgery (DGOOC) [18], where surgical treatment is considered if (1) the patient is unresponsive to maximum conservative treatment for at least 6 weeks, (2) shows progression of clinical symptoms, or (3) shows acute motor deficits, i.e., muscle force $\leq 3 / 5$ according to Medical Research Council (MRC) scales. Data were collected using the patients' digital health records (Cerner Millennium - Power Chart, Cerner Corporation 2011, Idstein, Germany) including demographics, baseline clinical and neurological characteristics, treatment details, and treatment outcomes of the patients. Pain values were assessed by Numeric Rating Scale (NRS) scores, "0" indicating "no pain" and "10" indicating "unbearable pain." American Association of Anesthesiologists (ASA) scores were evaluated preoperatively for classification of the general health status of each patient, reaching from score " 1 " (normal, healthy patient) to "5" (multimorbid patient who will not survive without surgery). These parameters were gathered at four different time points: the initial diagnosis, the third postoperative day, the day of discharge, and 6 weeks postoperatively. Data were documented according to institutional standards and the general standards according to the principles of good clinical practice (GCP). Due to inconsistency of long-term follow-up data, special attention was paid to short-term follow-up. Clinical outcome parameters assessed in this study included the occurrence of motor deficits pre- and postoperatively and at 6 weeks follow-up, as well as pain scales and consumption of pain killers at the exact same time points.

\section{Patient cohort}

Ninety-seven patients were identified and their data were analyzed retrospectively. All patients treated for lumbar disc herniation between 2010 and 2017 aged 25 or younger were considered for inclusion in our analysis. Four patients, all treated conservatively, all non-obese, were excluded, as follow-up organization in medically treated LDH is not standardized in our department and was less than 6 weeks in those cases. The main comparison in this analysis was performed between the obese and smoking groups $(\mathrm{O} 1+\mathrm{O} 2)$ and the remaining patients $(\mathrm{O} 3+\mathrm{NO})$.

The proportion of obese individuals (group $\mathrm{O}, n=18$ ) to non-obese individuals (group NO, $n=75$ ) was $19.4 \%$ and $80.6 \%$. This rate of obese individuals in our cohort $(19.4 \%)$ differs significantly from the rate of obese adolescents in the Central European overall population (3.87.1\%, RR 3.17, CI 1.32-7.6; $p<0.001$ ) [2, 3]. Fifty-eight $(62.4 \%)$ of all 130 patients were smokers. In addition, this rate shows a significant variation from the known percentage of smoking adolescents aged younger than $30(30.2 \%$, RR 2.0, CI 1.44-2.78; $p=0.01)$ [14]. The number of cigarettes per day was not significantly different between the two groups $(p=0.41$; see Table 1$)$. In total, $44.1 \%(n=41)$ of patients were female. The distinction of the distribution of ASA scores was significant between the two groups with better overall scores in the non-obese patient group. The most frequently affected disc level was L5/S1 $(n=50,53.8 \%)$ followed by $\mathrm{L} 4 / 5$ $(n=35,37.6 \%)$. Level L1/2 was treated one time $(n=1$, $1.1 \%)$, level L3/4 was affected two times $(n=2,2.2 \%)$, and "other" levels, meaning L5/6 in the appearance of a sacral transitional vertebra, were treated four times altogether $(n=4,4.3 \%)$. Lumbar sequestrectomy was performed as a standard in all patients $(n=93,100 \%)$. A translaminar approach was chosen in two patients $(2.7 \%)$, while the majority of patients was treated via an interlaminar approach $(n=73,97.3 \%)$. None of the patients experienced intra- or perioperative complications (i.e., hematoma, infection, cerebrospinal fluid leakage) (Table 1).

\section{Surgical procedure}

Surgery was performed under the same standardized surgical protocol by different trial designated surgeons. After induction of general endotracheal anesthesia and with the assistance of an operating microscope, a microsurgical sequesterectomy was performed, while the patient was in a prone position. In cases of non-dislocated, non-cranially herniated discs, the 
Table 1 Demographic details

\begin{tabular}{|c|c|c|c|c|}
\hline & & Group O $(n=18)$ & Group NO $(n=75)$ & \\
\hline Age & In years $(S D)$ & $21.3( \pm 1.5)$ & $22.2( \pm 2.3)$ & n.s. \\
\hline \multirow[t]{2}{*}{ Sex, $n(\%)$} & Male & $8(44.4)$ & $44(58.7)$ & n.s. \\
\hline & Female & $10(55.6)$ & $31(41.3)$ & n.s. \\
\hline BMI & In kg/m² (SD) & $32.8( \pm 3.5)$ & $23.8( \pm 2.8)$ & $p<0.01$ \\
\hline \multirow[t]{2}{*}{ ASA score, $n(\%)$} & ${ }^{\circ} 1$ & $4(22.2)$ & $69(92.0)$ & $p<0.01$ \\
\hline & ${ }^{\circ} 2$ & $14(77.8)$ & $6(8.0)$ & $p<0.01$ \\
\hline \multirow[t]{2}{*}{ Smoking, $n(\%)$} & & $12(66.7)$ & $46(61.3)$ & n.s. \\
\hline & Cigarettes/day (SD) & $10.3( \pm 8.6)$ & $8.8( \pm 9.3)$ & n.s. \\
\hline Duration of symptoms & In days (SD) & $95.1( \pm 76.0)$ & $104.0( \pm 76.4)$ & n.s. \\
\hline Duration of hospital stay & In days (SD) & $7.1( \pm 2.1)$ & $6.0( \pm 2.4)$ & $p<0.05$ \\
\hline \multirow[t]{5}{*}{ Level of disc herniation, $n(\%)$} & $\mathrm{L} 1 / 2$ & $1(5.6)$ & 0 & n.s. \\
\hline & $\mathrm{L} 3 / 4$ & $1(5.6)$ & $1(1.3)$ & n.s. \\
\hline & $\mathrm{L} 4 / 5$ & $5(27.8)$ & $30(40.0)$ & n.s. \\
\hline & $\mathrm{L} 5 / \mathrm{S} 1$ & $11(61.2)$ & $40(53.3)$ & n.s. \\
\hline & Other & 0 & $4(5.3)$ & n.s. \\
\hline Operative time & & $84.4( \pm 31.6)$ & $68.8( \pm 29.8)$ & n.s. \\
\hline Complications & In minutes (SD) & 0 & 0 & n.s. \\
\hline
\end{tabular}

$p$ values were calculated by comparison of the mean values of group $\mathrm{O}$ and group $\mathrm{NO}$

$n$ number of patients; $n . s$ not significant; $S D$ standard deviation

spinal canal was exposed by performing a standard interlaminar fenestration. A translaminar approach was preferred for cranially herniated discs [19]. Based on previous trials, only the herniated disc material was removed, and, whenever possible, the annulus defect was not entered [20]. Intraoperative and postoperative complications like revision surgery for reherniation, infection, or hematoma were recorded.

\section{Statistical analysis}

All patients with complete initial data were considered for inclusion in this retrospective analysis. All values are expressed as mean \pm standard deviation (SD). The Kolmogorov-Smirnov test was used for testing normal distribution. The unpaired Student's $t$ test and Mann-Whitney $U$ test were performed to analyze differences in clinical and demographic characteristics and in clinical outcome variables. Frequencies were compared by chi-square and Fisher's exact tests. Spearman's rho correlation $(r)$ was determined to assess the relationship between clinical outcome and demographic findings. A multivariate analysis of variance was performed to identify the coherence of combined findings and the clinical outcome. Relative risk ratio (RR) and 95\% confidence intervals (CI) were calculated for the particular proportion of obese and smoking individuals. The level of significance was set to $p<0.05$. All statistical evaluations were performed with SPSS Version 21.0 (IBM Corp., released 2012, IBM SPSS Statistics for Mac OS X, Version 21.0, NY, IBM Corp.).
Figures were designed using Microsoft Excel (Version 15.36 for Mac OS X, Microsoft Corporation 2017, Redmond, USA).

\section{Results}

The average duration of symptoms was $95 \pm 76$ days in group $\mathrm{O}$ vs. $104 \pm 76$ days in group $\mathrm{NO}(p=0.59)$. The mean length of hospital stay showed a significant difference between group $\mathrm{O}$ (7 days \pm 2 ) and group $\mathrm{NO}$ ( 6 days $\pm 2 ; p=0.01)$. Operative time showed a trend to longer surgery in group $\mathrm{O}(\mathrm{O} 84 \pm$ $31 \mathrm{~min}$ vs. NO $69 \pm 29 \mathrm{~min} ; p=0.06$ ).

Among the collected clinical outcome parameters, no significant differences between the two groups ( $\mathrm{O}$ and $\mathrm{NO})$ could be revealed for the extent of pain or motor deficit. Nevertheless, the data showed a trend to earlier recovery of motor deficits $(p=0.067)$ and pain scales in group NO $(p=$ 0.074; see Figs. 1 and 2). Results were comparable for both groups 6 weeks postoperatively $(p>0.05)$.

For a subgroup analysis (groups $\mathrm{O} 1, \mathrm{O} 2$, and $\mathrm{O} 3$ ), significant alternations could be found comparing the groups with each other, and also in correlation to the rest of our population (group NO). The duration of hospital stay was significantly longer in groups $\mathrm{O} 1$ and $\mathrm{O} 2$, when compared with groups $\mathrm{O} 3$ and NO ( $6 \pm 3$ days vs. $7 \pm 2$ days; $p=0.04)$. Obese smoking patients showed a trend of a higher incidence of motor deficits at diagnosis $(n=8 / 12,66.7 \%$ vs. $n=30 / 81,37.0 \% ; p=$ 0.063 ), and recovered significantly delayed, as seen in the rates of deficits 3 days postoperatively $(n=6 / 12,50 \%$ vs. 


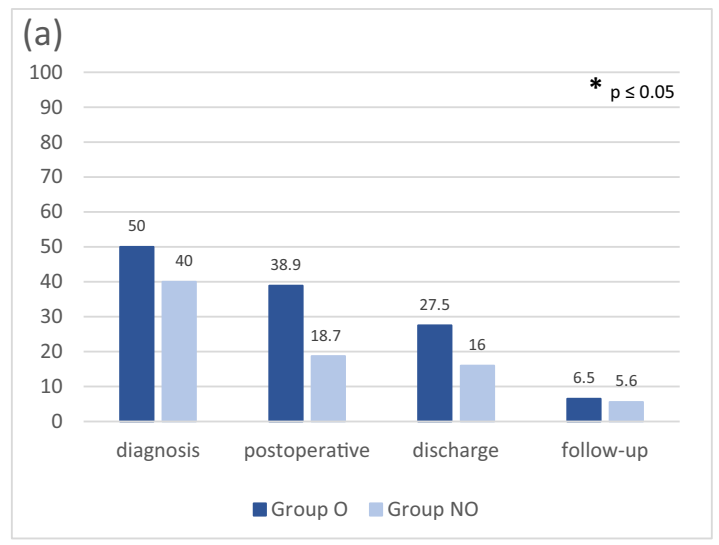

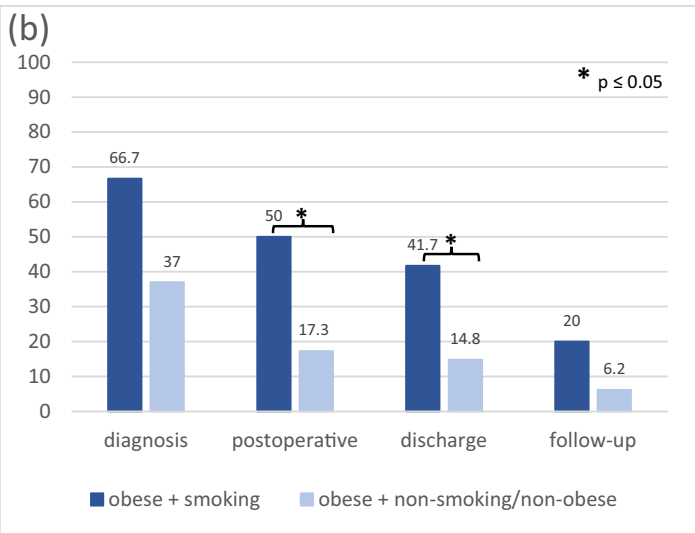

Fig. 1 Differences in the incidence of motor deficits (percent, $y$-axis): between group $\mathrm{O}$ and group $\mathrm{NO}(\mathbf{a})$, between obese plus smoking patients versus obese non-smoking/non-obese patients (b), and among

$n=14 / 81,17.3 \% ; p=0.015)$ and at discharge $(n=5 / 12$, $41.7 \%$ vs. $n=12 / 81,14.8 \% ; p=0.025)$. After 6 weeks, the differences resolved $(n=1 / 12,20 \%$ vs. $n=5 / 81,6.2 \% ; p=$ $0.69)$ (Fig. 1). No differences existed 6 weeks postoperatively $(n=0 / 6,0 \%$ vs. $n=0 / 6,0 \%)$.

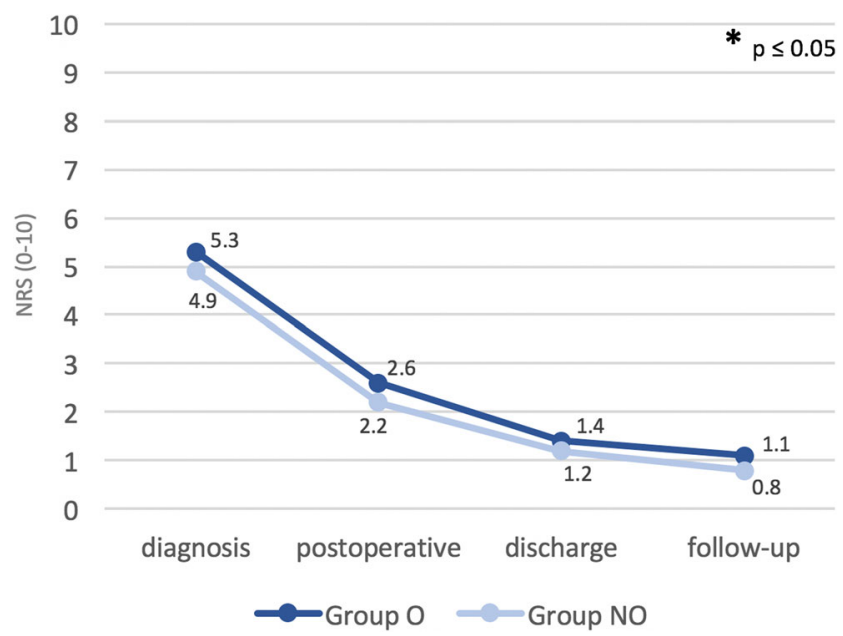

Fig. 2 Differences in pain values, assessed by the NRS among group O and group $\mathrm{NO}$ at four different time points $(x$-axis). Significant differences $(p<0.05)$ are marked by an asterisk

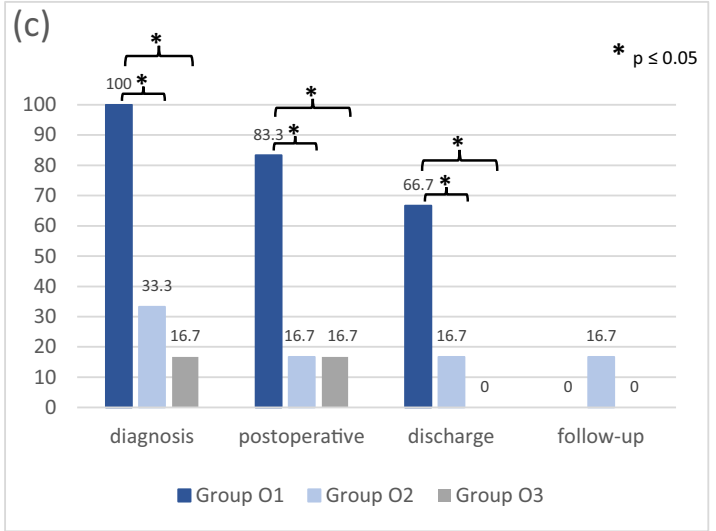

group $\mathrm{O} 1$ versus groups $\mathrm{O} 2$ and $\mathrm{O} 3$ at four different time points $(x-$ axis) (c). Significant differences $(p<0.05)$ are marked by an asterisk

Moreover, non-obese patients' pain outcomes at the 6 weeks follow-up were affected negatively by excessive smoking habits. Higher pain values $(0.7 \pm 1.1$ vs. $1.4 \pm 1.3$; $p=0.026)$, as well as the usage of analgesics $(n=2 / 60,3 \%$

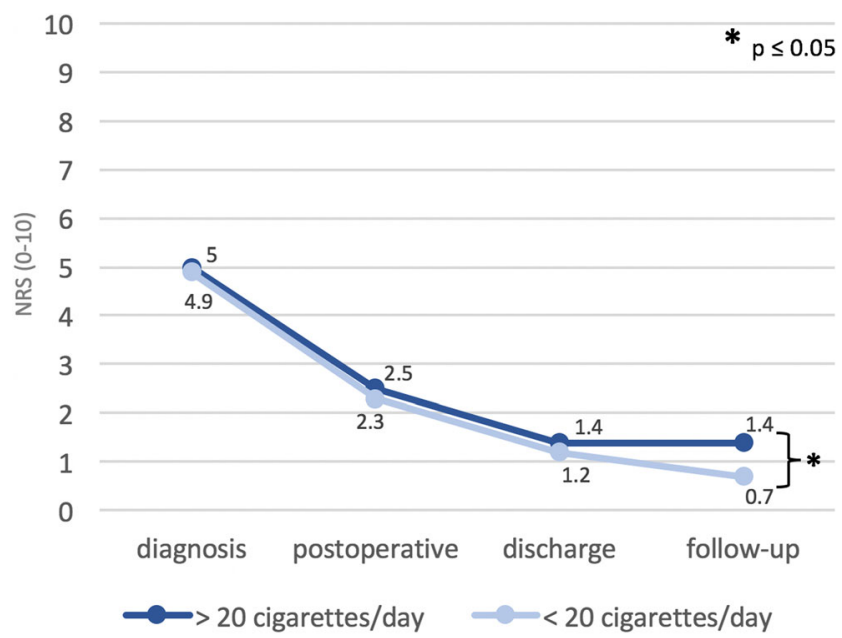

Fig. 3 Differences in pain values, assessed by the NRS (0-10, $y$-axis) among smoking and non-smoking patients at four different time points $(x$ axis). Significant differences $(p<0.05)$ are marked by an asterisk 
vs. $n=4 / 17,24 \% ; p=0.015)$, correlated with the consumption of $>20$ cigarettes per day (Fig. 3 ).

Differences in the recovery of motor deficits maintained significant in obese patients with a consumption of $>20$ cigarettes per day (group O1). Values were compared with those of obese patients smoking 20 cigarettes or fewer (group O2), and to obese, non-smoking patients (group O3; see Fig. 2). Group O1 showed significantly more motor deficits in comparison with group $\mathrm{O} 3$ at initial diagnosis $(n=6 / 6,100 \%$ vs. $n=1 / 6,16.7 \% ; p=0.020)$, on the third postoperative day $(n=$ $5 / 6,83.3 \%$ vs. $n=1 / 6,16.7 \% ; p=0.021)$ and at discharge ( $n=4 / 6,66.7 \%$ vs. $n=0 / 6 ; 0 \% ; p=0.014)$. Group O1 vs. group $\mathrm{O} 2$ also showed significant differences in favor of group O2: motor deficits at diagnosis $(n=6 / 6,100 \%$ vs. $n=$ $2 / 6,33.3 \% ; p=0.014)$ and on the third postoperative day $(n=$ $5 / 6,83.3 \%$, vs. $n=1 / 6,16.7 \% ; p=0.021$ ) were more frequent among group $\mathrm{O} 1$. The differences remained at the day of discharge and at 6 weeks follow-up, but failed to reach significance $(n=4 / 6,66.7 \%$ vs. $n=1 / 6,16.7 \% ; p=0.079 ; n=0 / 6$, $0 \%$ vs. $n=1 / 6,16.7 \% ; p=0.29$, respectively).

A multivariate analysis revealed that the combination of overweight and heavy smoking resulted not only in a slower recovery of motor deficits $(p=0.07)$ but also in significantly higher pain values $(p=0.037)$, and therefore in a significantly more frequent usage of analgesics at 6 weeks follow-up ( $p=0.004)$.

No gender differences were found in the presentation and outcome of lumbar disc herniation.

\section{Discussion}

We report the results of the first retrospective study investigating the influence of obesity and smoking on individuals aged 25 years or less, suffering from LDH requiring treatment.

In total, $19.4 \%$ of treated patients presented with a BMI $\geq$ $30 \mathrm{~kg} / \mathrm{m}^{2}$, whereby the overall prevalence for obesity at the investigated age level ranges from 3.8 to $7.1 \%$ in Central Europe $[2,3]$. This reveals a significantly higher rate of obese individuals among our cohort and may demonstrate the impact of obesity on the genesis of lumbar disc herniations among young individuals. These findings agree with previous studies among older patients, which identified obesity as a significant risk factor for the development of spinal diseases, including intervertebral disc degeneration [4, 21, 22]. Nevertheless, the question whether an elevated BMI precedes or follows first clinical manifestations could not be answered, as beginning symptoms may lead to lower levels of physical activity and thus result in higher levels of body weight [6]. In our cohort, obese patients were solely treated surgically [9, 22], although higher perioperative risks have been described [8]. The shorter mean duration of symptoms until treatment starts in obese patients could assume that obese patients are (subjectively) more disabled by symptoms [23]. Furthermore, pain therapy is challenging, not only due to differences in drug metabolism $[24,25]$ that may consequently lead to earlier and more aggressive treatments. Nevertheless, none of our investigated patients experienced considerable perioperative complications. Thus, the hypothesis of higher risks concerning surgical intervention $[7,8]$ in obese patients could not be confirmed for patients aged 25 years or younger. Still, the fact that patients presenting with obesity showed significantly longer hospital stays cannot be neglected and may support the theory of delayed recovery.

Differently, the improvement of preoperative motor deficits depends on various factors like the duration of symptoms and on BMI [26]: the obese patient group in our cohort experienced symptoms for a shorter period but needed the same amount of time to recover from motor deficits as non-obese patients. Therefore, the overall factor of time and its impact on short-term recovery may be neglected for young patients presenting with obesity. Yet, the finding of the impact of time on motor deficit, its outcome, and on long-term recovery may not be valid as both factors could not be tested precisely enough for our study cohort. In general, patients with herniation of a lumbar disc, which causes mild or severe weakness, show a complete or almost complete recovery of strength after surgery [27]. In our patient cohort, the direct correlation between surgery and conservative treatment was not done, due to a missing medically treated population. For the general population, the 1-year outcomes were similar for patients assigned to early surgery and those assigned to conservative treatment [28]. Nevertheless, the rates of pain relief and of perceived recovery were faster for those assigned to early surgery. However, the circumstance of a higher BMI leading to a poorer neurological outcome could be proven to some extent.

Not only does the number of obese individuals in our cohort differ significantly from the known rate among the European population, but also the number of regular smokers was significantly higher in our cohort than known in adolescents aged 30 or younger (62.4\% vs. $30.2 \%$ ). Also, this finding may demonstrate the negative impact of regular smoking, not only on the recovery process but also on the development of lumbar disc disease in young individuals. Smoking has already been identified as a risk factor for the development of $\mathrm{LDH}[15,16]$ as well as for the risk of re-herniation [17]. Likewise, the negative impact of smoking on the improvement of the functional status is already known [29]. Nevertheless, those factors were not tested in young individuals, as the recovery of pain especially seems to be negatively affected by heavy smoking, reaching a level of significance at 6 weeks of follow-up.

The risk of suffering from a motor deficit and experiencing a worse outcome or a delayed improvement rises for obese and smoking patients. Differences in impairment and postoperative deficits increase with rising numbers of cigarettes per day. When compared with obese non-smoking patients, the group presenting with obesity plus smoking behavior initially suffered from motor deficits significantly more often. Differences were 
sustained at 3 days postoperatively, but nearly adjusted at discharge and continued to improve until 6 weeks postoperatively. Incidence and adjustment rates worsened when obese patients were smoking $>20$ cigarettes per day. We might confirm a negative effect of obesity plus smoking on the incidence of motor deficits in young patients. The same negative effect could be shown on the improvement of motor deficits, but only for a short period of time. Nevertheless, the impact of smoking not only on motor recovery but also on pain improvement cannot be ignored. Heavily smoking patients showed significantly worse pain outcomes, as well as a significantly more frequent use of analgesic medication after 6 weeks of follow-up.

Underlying mechanisms for a delay in motor deficit regeneration may include the chronic inflammatory conditions in our patient group, caused by both smoking and obesity [30-32]. Previous studies suggest an influence of high levels of cytokines not only on disc degeneration [33] but also on motor recovery and pain $[34,35]$. Long-time consequences could not be determined properly in this retrospective setting. Nevertheless, causes can only be assumed and definitely need further investigation by prospective clinical trials.

Our retrospective results support the hypothesis that smoking is associated with poorer outcome after treatment for LDH, especially in the presence of obesity. Nevertheless, those results seem to have limited applicability for young patients in general, as individuals in both groups show similar outcomes after 6 weeks of follow-up. However, several limitations have to be considered when interpreting our results, including the retrospective study design, the different surgeons performing surgeries, the relatively small number of patients, and the short period of follow-up, as re-herniation rates and subjective longterm satisfaction could not be assessed. All patients were treated surgically and therefore the aspects of a conservative treatment in obese young individuals are mostly missing.

\section{Conclusion}

We could demonstrate the negative impact of obesity and smoking on occurrence of LDH, but not precisely on the recovery of radiculopathy in young adults. Hence, when combined with heavy smoking, delayed recovery also applies to individuals aged 25 or younger and even isolated smoking may increase the risk to develop a LDH in individuals aged 30 or less.

Funding Information Open access funding provided by University of Innsbruck and Medical University of Innsbruck.

\section{Compliance with ethical standards}

Conflict of interest The authors declare that they have no conflict of interest.
Ethical approval No ethical approval was required, as this is a retrospective analysis.

Informed consent No informed consent was required, as this is a retrospective analysis without any traceable patient data.

Open Access This article is distributed under the terms of the Creative Commons Attribution 4.0 International License (http:// creativecommons.org/licenses/by/4.0/), which permits unrestricted use, distribution, and reproduction in any medium, provided you give appropriate credit to the original author(s) and the source, provide a link to the Creative Commons license, and indicate if changes were made.

\section{References}

1. Lobstein T, Baur L, Uauy R (2004) Obesity in children and young people: a crisis in public health. Obesity Rev 5(Suppl 1):4-85

2. Österreichische Gesundheitsbefragung 2014 - Bundesministerium für Gesundheit, Wien, Österreich - „Hauptergebnisse des Austrian Health Interview Survey (ATHIS) und methodische Dokumentation" [Internet] 2015 [cited on 10.01.2018] Available from: https://www.bmgf.gv.at/cms/home/attachments/1/6/8/ CH1066/CMS1448449619038/gesundheitsbefragung_2014.pdf

3. GEDA 2012 - Robert Koch Institut, Berlin, Germany - Beiträge zur Gesundheitsberichtserstattung des Bundes - Daten und Fakten: Ergebnisse der Studie „Gesundheit in Deutschland aktuell 2012” [Internet] 2014 [cited on 10.08.2017] Available from: https://www. rki.de/DE/Content/Gesundheitsmonitoring/ Gesundheitsberichterstattung/GBEDownloadsF/Geda2012/ uebergewicht adipositas.pdf? blob=publicationFile

4. Sheng B, Feng C, Zhang D, Spitler H, Shi L (2017) Associations between obesity and spinal diseases: a medical expenditure panel study analysis. Int J Environ Res Public Health 14(2)

5. Fransen M, Woodward M, Norton R, Coggan C, Dawe M, Sheridan $\mathrm{N}$ (2002) Risk factors associated with the transition from acute to chronic occupational back pain. Spine (Phila Pa 1976) 27(1):92-98

6. Samartzis D, Karppinen J, Mok F, Fong DY, Luk KD, Cheung KM (2011) A population-based study of juvenile disc degeneration and its association with overweight and obesity, low back pain, and diminished functional status. J Bone Joint Surg Am 93(7):662-670

7. Meredith DS, Huang RC, Nguyen J, Lyman S (2010 Jul) Obesity increases the risk of recurrent herniated nucleus pulposus after lumbar microdiscectomy. Spine J 10(7):575-580

8. Patel N, Bagan B, Vadera S, Maltenfort MG, Deutsch H, Vaccaro AR, Harrop J, Sharan A, Ratliff JK (2007) Obesity and spine surgery: relation to perioperative complications. J Neurosurg Spine. 6(4):291-297

9. Rihn JA, Kurd M, Hilibrand AS, Lurie J, Zhao W, Albert T, Weinstein J (2013) The influence of obesity on the outcome of treatment of lumbar disc herniation: analysis of the Spine Patient Outcomes Research Trial (SPORT). J Bone Joint Surg Am 95(1):1-8

10. Strömqvist F, Strömqvist B, Jönsson B, Karlsson MK (2016) The outcome of lumbar disc herniation surgery is worse in old adults than in young adults. Acta Orthop 87(5):516-521

11. Lagerbäck T, Elkan P, Möller H, Grauers A, Diarbakerli E, Gerdhem P (2015) An observational study on the outcome after surgery for lumbar disc herniation in adolescents compared with adults based on the Swedish Spine Register. Spine J 15(6):1241-1247

12. Tschugg A, Löscher WN, Lener S, Wildauer M, Hartmann S, Neururer S, Thomé C (2017) Gender differences after lumbar sequestrectomy: a prospective clinical trial using quantitative sensory testing. Eur Spine J 26(3):857-864 
13. Tschugg A, Lener S, Hartmann S, Wildauer M, Löscher WN, Neururer S, Thomé C (2017, Jan 13) Preoperative sport improves the outcome of lumbar disc surgery: a prospective monocentric cohort study. Neurosurg Rev

14. Österreichische Gesundheitsbefragung 2014 - Bundesministerium für Gesundheit, Wien, Österreich - „Hauptergebnisse des Austrian Health Interview Survey (ATHIS) und methodische Dokumentation" [Internet] 2015 [cited on 22.01.2018] Available from: https://www.statistik.at/web_de/statistiken/menschen_und gesellschaft/gesundheit/gesundheitsdeterminanten/rauchen/ 105592.html

15. Huang W, Qian Y, Zheng K, Yu L, Yu X (2016 Jan) Is smoking a risk factor for lumbar disc herniation? Eur Spine J 25(1):168-176

16. Mattila VM, Saarni L, Parkkari J, Koivusilta L, Rimpelä A (2008) Early risk factors for lumbar discectomy: an 11-year follow-up of 57,408 adolescents. Eur Spine J 17(10):1317-1323

17. Schumann B, Bolm-Audorff U, Bergmann A, Ellegast R, Elsner G, Grifka J, Haerting J, Jäger M, Michaelis M, Seidler A (2010) Lifestyle factors and lumbar disc disease: results of a German multi-center case-control study (EPILIFT). Arthritis Res Ther 12(5):R193

18. Diener HC, Weimar C, Berlit P et al (2012) Leitlinien für Diagnostik und Therapie in der Neurologie; Georg Thieme Verlag, 5th edn. Stuttgart, New York, pp 908-920

19. Vanni D, Galzio R, Kazakova A, Guelfi M, Pantalone A, Salini V, Magliani V (2015) Technical note: microdiscectomy and translaminar approach. J Spine Surg 1(1):44-49 Review

20. Thomé C, Barth M, Scharf J, Schmiedek P (2005 Mar) Outcome after lumbar sequestrectomy compared with microdiscectomy: a prospective randomized study. J Neurosurg Spine 2(3):271-278

21. Kalichman L, Guermazi A, Li L, Hunter DJ (2009) Association between age, sex, BMI and CT-evaluated spinal degeneration features. J Back Musculoskelet Rehabil 22(4):189-195

22. Böstman OM (1994 Oct) Prevalence of obesity among patients admitted for elective orthopaedic surgery. Int J Obes Relat Metab Disord 18(10):709-713

23. Järvimäki V, Kautiainen $H$, Haanpää $M$, Alahuhta $S$, Vakkala $M$ (2016 Jan) Obesity has an impact on outcome in lumbar disc surgery. Scand J Pain 10:85-89

24. Lloret-Linares C, Lopes A, Declèves X, Serrie A, Mouly S, Bergmann JF, Perrot S (2013 Sep) Challenges in the optimisation of post-operative pain management with opioids in obese patients: a literature review. Obes Surg 23(9):1458-1475

25. Brill MJ, Diepstraten J, van Rongen A, van Kralingen S, van den Anker JN, Knibbe CA (2012 May 1) Impact of obesity on drug metabolism and elimination in adults and children. Clin Pharmacokinet 51(5):277-304

26. Petr O, Glodny B, Brawanski K, Kerschbaumer J, Freyschlag C, Pinggera D, Rehwald R, Hartmann S, Ortler M, Thomé C (2017 Jun 27) Immediate versus delayed surgical treatment of lumbar disc herniation for acute motor deficits: the impact of surgical timing on functional outcome. Spine (Phila Pa 1976)

27. Postacchini F, Giannicola G, Cinotti G (2002) Recovery of motor deficits after microdiscectomy for lumbar disc herniation. J Bone Joint Surg Br 84(7):1040-1045

28. Peul WC, van Houwelingen HC, van den Hout WB, Brand R, Eekhof JA, Tans JT et al (2007) Leiden-The Hague Spine Intervention Prognostic Study Group. Surgery versus prolonged conservative treatment for sciatica. N Engl J Med 356(22):22452256

29. Kerr D, Zhao W, Lurie JD (2015) What are long-term predictors of outcomes for lumbar disc herniation? A randomized and observational study. Clin Orthop Relat Res 473(6):1920-1930

30. Wang Y, Huang F (2015) N-3 polyunsaturated fatty acids and inflammation in obesity: local effect and systemic benefit. Biomed Res Int 2015:581469

31. Yanbaeva DG, Dentener MA, Creutzberg EC, Wesseling G, Wouters EF (2007) Systemic effects of smoking. Chest. 131(5): 1557-1566 Review

32. Das UN (2001) Is obesity an inflammatory condition? Nutrition. 17(11-12):953-966

33. Mern DS, Beierfu $\beta$ A, Fontana J, Thomé C, Hegewald AA (2014) Imbalanced protein expression patterns of anabolic, catabolic, anticatabolic and inflammatory cytokines in degenerative cervical disc cells: new indications for gene therapeutic treatments of cervical disc diseases. PLoS One 9(5):e96870

34. Nadeau S, Filali M, Zhang J, Kerr BJ, Rivest S, Soulet D, Iwakura Y, de Rivero Vaccari JP, Keane RW, Lacroix S (2011) Functional recovery after peripheral nerve injury is dependent on the proinflammatory cytokines IL- $1 \beta$ and TNF: implications for neuropathic pain. J Neurosci 31(35):12533-12542

35. Risbud MV, Shapiro IM (2014 Jan) Role of cytokines in intervertebral disc degeneration: pain and disc content. Nat Rev Rheumatol 10(1):44-56

Publisher's note Springer Nature remains neutral with regard to jurisdictional claims in published maps and institutional affiliations. 